\title{
Distortions in Fetal Growth Standards
}

\author{
RICHARD L. NAEYE ${ }^{(19)}$ AND JOSEPH B. DIXON \\ Department of Pathology and Research Computing Facility, M. S. Hershey Medical Center, The Pennsylvania State \\ University College of Medicine, Hershey, Pennsylvania, USA
}

\begin{abstract}
Summary
The study analyzed several errors incorporated in widely used fetal growth standards. Such standards contain measurements from many infants who died as neonates. The present study found many of these nonsurvivors to be growth retarded so new standards were developed which contain only measurements from survivors. The study also found that weights and other body measurements of prematurely born neonates cluster at intervals consistent with maternal vaginal bleeding at monthly intervals in early pregnancy. Such bleeding is ofter mistaken for the last menstrual period. To avoid this error, the probability plot method was used to separate the clusters of measurements at each gestational age. The cluster with the lowest values at each gestational age was used as the data base for the new growth standards. Standard deviations from most mean values in the new growth standards are much smaller than are such deviations in the older standards.
\end{abstract}

\section{Speculation}

At present there seems to be no completely valid method available to determine normal fetal growth using measurements from neonates because there is no assurance that prematurely born neonates are normally grown. Ultrasound and other modalities may eventually solve this problem by providing accurate, sequential in utero measurements of normal fetuses.

Fetal growth standards used throughout the world are based on body measurements of neonates born at various gestational ages. Standard deviations (SD) from mean birth weight values are relatively larger in preterm than in term infants in all of these older growth standards $(1,2,4,7,8,16)$. This raises the possibility that too many abnormally grown infants or those assigned inaccurate gestational ages have been included in the preterm standards because it is known that variations in fetal growth are greater in late than in earlier gestation $(5,11,12)$. The present study explored both the causes and possible remedies for these problems.

\section{PATIENTS AND METHODS}

The Collaborative Perinatal Project of the National Institute of Neurological and Communicative Disorders and Stroke provides a unique opportunity to study pregnancy and its outcome prospectively. It followed the course of pregnancies in 12 hospitals in various parts of the United States between 1959 and 1966 and recorded events of gestation, labor, delivery, and the neonatal period $(14,15)$. Measurements from 48,239 single born neonates were used in the analyses. All were alive and well at 1 year of age without disorders known to distort fetal growth. Such infants are subsequently termed "survivors." They included 24,698 males, 23,541 females, 22,286 blacks, 22,190 whites, and 3,763 of other racial and ethnic origins. There were great variations in the socioeconomic status of the infants' families (14).

Gestational ages were computed as the time between the first day of the last recorded menstrual period and the date of delivery, rounded to whole weeks. Some of these infants were older than their calculated gestational ages because monthly bleeding during early pregnancy is sometimes taken for the last mentrual period. Previous authors of fetal growth standards have used a variety of methods to exclude these infants who are older than their calculated gestational ages. Gruenwald used a bimodal curve in which he excluded the upper cluster, Lubchenco used a scattergram and review of clinical course, Babson and Brenner used the results of obstetric histories and maternal physical examinations, whereas Usher added clinical tests of the neonate's maturity to establish gestational ages $(1,2,4,8,16)$. The present study attempted to develop a method for selecting infants to be included in fetal growth standards that was not dependent on case by case assessments of clinical findings.

Table 1. Birth weights in percentage of control values ${ }^{1}$

\begin{tabular}{|c|c|c|c|c|c|}
\hline & \multicolumn{4}{|c|}{ Gestational age at death (weeks) } & \multirow[b]{2}{*}{ No. of cases } \\
\hline & $28-31$ & $32-34$ & $35-37$ & $38-43$ & \\
\hline \multicolumn{6}{|l|}{ Subgroup A } \\
\hline Placenta previa & $71 \pm 23^{2}$ & $77 \pm 11^{3}$ & & $73 \pm 31^{3}$ & 28 \\
\hline Abruptio placentae & $86 \pm 29^{4}$ & $89 \pm 22^{4}$ & $84 \pm 19^{4}$ & $89 \pm 9^{4}$ & 136 \\
\hline Amniotic fluid infection syndrome & $85 \pm 22^{4}$ & $72 \pm 35^{2}$ & $93 \pm 21$ & $90 \pm 17$ & 155 \\
\hline Premature rupture of membranes & $96 \pm 35$ & $98 \pm 21$ & $82 \pm 17^{2}$ & $92 \pm 25$ & 127 \\
\hline Umbilical cord knots & $79 \pm 25^{2}$ & $63 \pm 19^{3}$ & $76 \pm 10^{3}$ & $86 \pm 22$ & 43 \\
\hline Fetal hypoxia of unknown cause & $71 \pm 27^{2}$ & $65 \pm 14^{3}$ & $84 \pm 27^{4}$ & $85 \pm 23$ & 173 \\
\hline Subgroup B: Birth trauma & $106 \pm 16$ & & $98 \pm 18$ & $104 \pm 19$ & 21 \\
\hline Controls & $100 \pm 8$ & $100 \pm 9$ & $100 \pm 10$ & $100 \pm 11$ & 48,289 \\
\hline
\end{tabular}

\footnotetext{
${ }^{1}$ Nonsurviving infants with disorders that existed before the onset of labor (subgroup A) had undergrown bodies by comparison with liveborn infants who survived, i.e., control infants. By contrast, infants who died as the consequence of birth trauma (subgroup B) had body measurements close to those of the surviving control infants. All values are \pm 1 SD. Student's $t$-test was used to evaluate statistical significance.

${ }^{2} P<0.02$ compared with control group.

${ }^{3} P<0.005$ compared with control group.

${ }^{4} P<0.05$ compared with control group.
} 
At each gestational age calculated from menses the number of cases was plotted at 20 -g intervals of body weight. Before 38 weeks of gestation, cases were found to cluster at birth weight intervals consistent with vaginal bleeding at monthly intervals during early pregnancy. At each gestational age, the lowest weight cluster was used as the data base for that gestational age on the assumption that this cluster represented cases without pregnancy bleeding. The mean and SD for each cluster were determined by the probability plot method $(3,6)$. The same method was used to determine standards for placental weight, body length, and head circumference at each gestational age. Body and placental measurements from neonates born 38 weeks or more after the last recorded menstrual period were assumed to be correct and were used directly as the data base for the growth standards at those ages.

Published growth standards include measurements from infants who died as neonates. An effort was made to determine whether the inclusion of such cases distorts fetal growth standards. We compared fetal growth established for survivors by the cluster method with the growth of two subgroups who died as neonates. These two subgroups were selected because cases like them were likely included in previous growth standards. Subgroup A in-

Table 2. Fetal body weight percentiles from 28 weeks of gestation to term based on birth weights of infants who survived

\begin{tabular}{crrrrrr}
\hline & \multicolumn{5}{c}{ Body weight (g) } & No. of \\
\cline { 2 - 5 } age (weeks) & 10 th $^{1}$ & 25 th $^{1}$ & $50 \mathrm{th}^{1}$ & $75 \mathrm{th}^{1}$ & $90 \mathrm{th}^{1}$ & cases \\
\hline 28 & 967 & 1085 & 1165 & 1245 & 1363 & 29 \\
29 & 1124 & 1226 & 1295 & 1364 & 1466 & 42 \\
30 & 1232 & 1356 & 1440 & 1524 & 1648 & 68 \\
31 & 1386 & 1515 & 1601 & 1687 & 1816 & 111 \\
32 & 1534 & 1675 & 1769 & 1863 & 2004 & 223 \\
33 & 1703 & 1854 & 1955 & 2056 & 2207 & 303 \\
34 & 1791 & 2012 & 2160 & 2308 & 2529 & 597 \\
35 & 2008 & 2235 & 2387 & 2539 & 2766 & 1033 \\
36 & 2121 & 2420 & 2621 & 2822 & 3121 & 1208 \\
37 & 2354 & 2667 & 2878 & 3089 & 3402 & 2305 \\
38 & 2570 & 2898 & 3119 & 3340 & 3668 & 4376 \\
39 & 2676 & 3039 & 3283 & 3527 & 3890 & 9317 \\
40 & 2776 & 3143 & 3388 & 3633 & 4000 & 11543 \\
41 & 2778 & 3190 & 3466 & 3742 & 4154 & 9378 \\
42 & 2778 & 3209 & 3498 & 3787 & 4218 & 5625 \\
43 & 2780 & 3210 & 3499 & 3788 & 4218 & 2081 \\
\hline
\end{tabular}

${ }^{1}$ Percentile.

Table 3. Fetal body length percentiles from 28 weeks of gestation to term based on birth measurements of infants who survived

\begin{tabular}{cccccc}
\hline $\begin{array}{c}\text { Gesta- } \\
\text { tional age } \\
\text { (weeks) }\end{array}$ & \multicolumn{5}{c}{ Crown heel length $(\mathrm{cm})$} \\
\cline { 2 - 6 } & $10 \mathrm{th}^{1}$ & $25 \mathrm{th}^{1}$ & $50 \mathrm{th}^{1}$ & $75 \mathrm{th}^{1}$ & $90 \mathrm{th}^{1}$ \\
\hline 28 & 36.2 & 37.3 & 38.0 & 38.7 & 39.8 \\
29 & 37.3 & 38.3 & 39.0 & 39.7 & 40.7 \\
30 & 38.7 & 39.7 & 40.3 & 40.9 & 41.9 \\
31 & 39.4 & 40.6 & 41.4 & 42.2 & 43.4 \\
32 & 40.6 & 41.7 & 42.5 & 43.3 & 44.4 \\
33 & 41.8 & 43.1 & 43.9 & 44.7 & 46.0 \\
34 & 42.8 & 44.3 & 45.3 & 46.3 & 47.8 \\
35 & 44.0 & 45.6 & 46.7 & 47.8 & 49.4 \\
36 & 45.2 & 46.9 & 48.0 & 49.1 & 50.8 \\
37 & 46.1 & 47.8 & 48.9 & 50.0 & 51.7 \\
38 & 46.7 & 48.5 & 49.7 & 50.9 & 52.7 \\
39 & 47.0 & 48.8 & 50.0 & 51.2 & 53.0 \\
40 & 47.1 & 49.1 & 50.4 & 51.7 & 53.7 \\
41 & 47.1 & 49.3 & 50.7 & 52.1 & 54.3 \\
42 & 47.1 & 49.3 & 50.8 & 52.3 & 54.5 \\
43 & 47.2 & 49.4 & 50.9 & 52.4 & 54.6 \\
\hline 1
\end{tabular}

${ }^{1}$ Percentile.
Table 4. Fetal head circumference percentiles from 28 weeks of gestation to term based on birth measurements of infants who survived

\begin{tabular}{cccccc}
\hline \multirow{2}{*}{$\begin{array}{c}\text { Gesta- } \\
\text { tional age }\end{array}$} & \multicolumn{5}{c}{ Head circumference $(\mathrm{cm})$} \\
\cline { 2 - 6 } (weeks) & $10 \mathrm{th}^{1}$ & $25 \mathrm{th}^{1}$ & $50 \mathrm{th}^{1}$ & $75 \mathrm{th}^{1}$ & $90 \mathrm{th}^{1}$ \\
\hline 28 & 24.4 & 25.3 & 26.0 & 26.7 & 27.6 \\
29 & 25.4 & 26.3 & 26.9 & 27.5 & 28.4 \\
30 & 26.5 & 27.3 & 27.9 & 28.5 & 29.3 \\
31 & 27.1 & 28.0 & 28.6 & 29.2 & 30.1 \\
32 & 28.0 & 28.8 & 29.3 & 29.8 & 30.6 \\
33 & 28.8 & 29.6 & 30.1 & 30.6 & 31.4 \\
34 & 29.4 & 30.2 & 30.8 & 31.4 & 32.2 \\
35 & 30.2 & 31.0 & 31.6 & 32.2 & 33.0 \\
36 & 30.8 & 31.8 & 32.4 & 33.0 & 34.0 \\
37 & 31.4 & 32.4 & 33.1 & 33.8 & 34.8 \\
38 & 31.8 & 32.9 & 33.6 & 34.3 & 35.4 \\
39 & 31.9 & 33.0 & 33.8 & 34.6 & 35.7 \\
40 & 32.0 & 33.3 & 34.1 & 34.9 & 36.2 \\
41 & 32.0 & 33.3 & 34.2 & 35.1 & 36.4 \\
42 & 32.0 & 33.4 & 34.3 & 35.2 & 36.6 \\
43 & 32.1 & 33.4 & 34.3 & 35.2 & 36.5 \\
\hline 1
\end{tabular}

${ }^{1}$ Percentile.

Table 5. Fetal placental weight percentiles from 28 weeks of gestation to term based on cases in which infants survived

\begin{tabular}{cccccc}
\hline $\begin{array}{c}\text { Gesta- } \\
\text { tional age } \\
\text { (weeks) }\end{array}$ & \multicolumn{5}{c}{ Placental weights (g) } \\
\cline { 2 - 6 } 28 & 10 th $^{1}$ & 25 th $^{1}$ & 50 th $^{1}$ & 75 th $^{1}$ & 90 th $^{1}$ \\
\hline 217 & 242 & 259 & 276 & 301 \\
30 & 232 & 257 & 273 & 289 & 314 \\
31 & 236 & 265 & 284 & 303 & 332 \\
32 & 243 & 278 & 301 & 324 & 359 \\
33 & 262 & 296 & 319 & 342 & 376 \\
34 & 274 & 311 & 336 & 361 & 398 \\
35 & 289 & 324 & 353 & 382 & 424 \\
36 & 288 & 336 & 368 & 400 & 447 \\
37 & 297 & 364 & 387 & 427 & 486 \\
38 & 304 & 377 & 409 & 454 & 521 \\
39 & 304 & 383 & 436 & 475 & 548 \\
40 & 305 & 387 & 442 & 489 & 568 \\
41 & 306 & 393 & 451 & 509 & 579 \\
42 & 306 & 396 & 457 & 518 & 696 \\
43 & 307 & 398 & 459 & 520 & 611 \\
\hline 1
\end{tabular}

${ }^{1}$ Percentile.

cluded infants with common fetal disorders not previously known to be associated with intrauterine growth retardation, i.e., bacterial infections of the amniotic fluid, abruptio placentae, premature rupture of the membranes, placenta previa, umbilical cord knots, and fetal hypoxia of unknown cause. The numerically much smaller subgroup B included infants who died as a consequence of intrapartum trauma, mainly tentorial tears. Criteria for all these diagnoses have been previously published (9). The two subgroups constitute about $55 \%$ of all liveborn infants who subsequently died within the first month of life (9). The other $45 \%$ of nonsurvivors have diagnoses well known to be often associated with abnormal fetal growth, i.e., major congenital malformations, Rh erythroblastosis fetalis, large placental infarcts, congenital rubella, syphilis, cytomegalovirus disease and several other disorders (9).

Neonates in subgroup $\mathrm{A}$ had undergrown bodies by comparison with the survivors, particularly at the earlier gestational ages (Table 1). By contrast, infants who died as the consequence of intrapartum trauma (subgroup B) had body measurements very close to those for the surviving control infants (Table 1). As subgroup $A$ is much larger than subgroup $B$, it seemed wise to exclude all nonsurvivors from fetal growth standards and we did so for the current standards. 


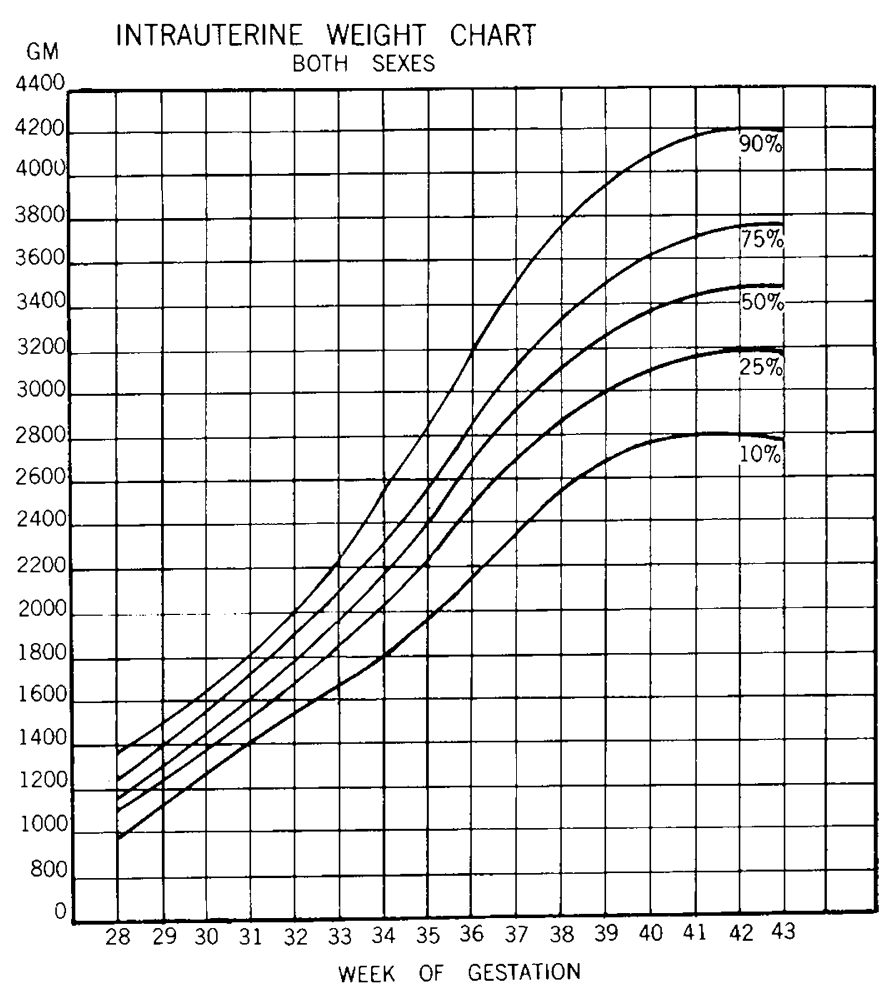

Fig. 1. Fetal body weight percentiles from $28-43$ weeks of gestation.

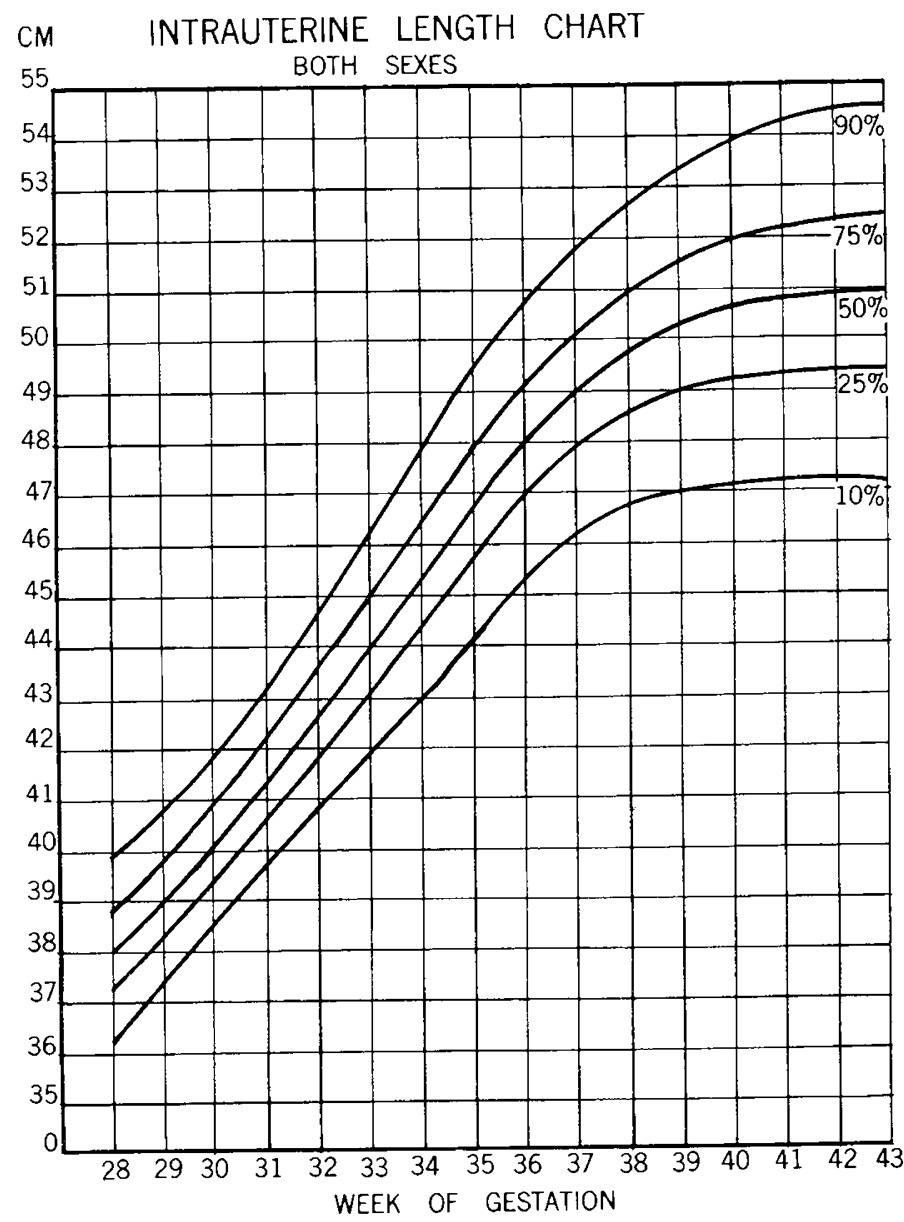

Fig. 2. Fetal body length percentiles from $28-43$ weeks of gestation.

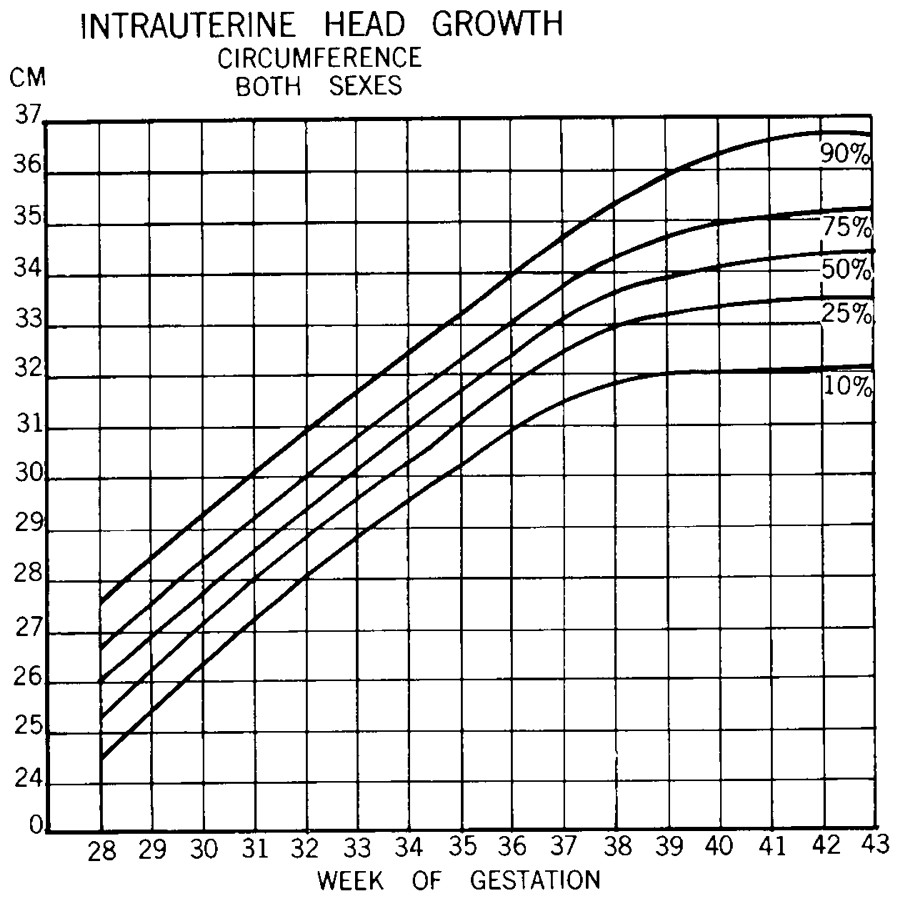

Fig. 3. Fetal head circumference percentiles from $28-43$ weeks of gestation.

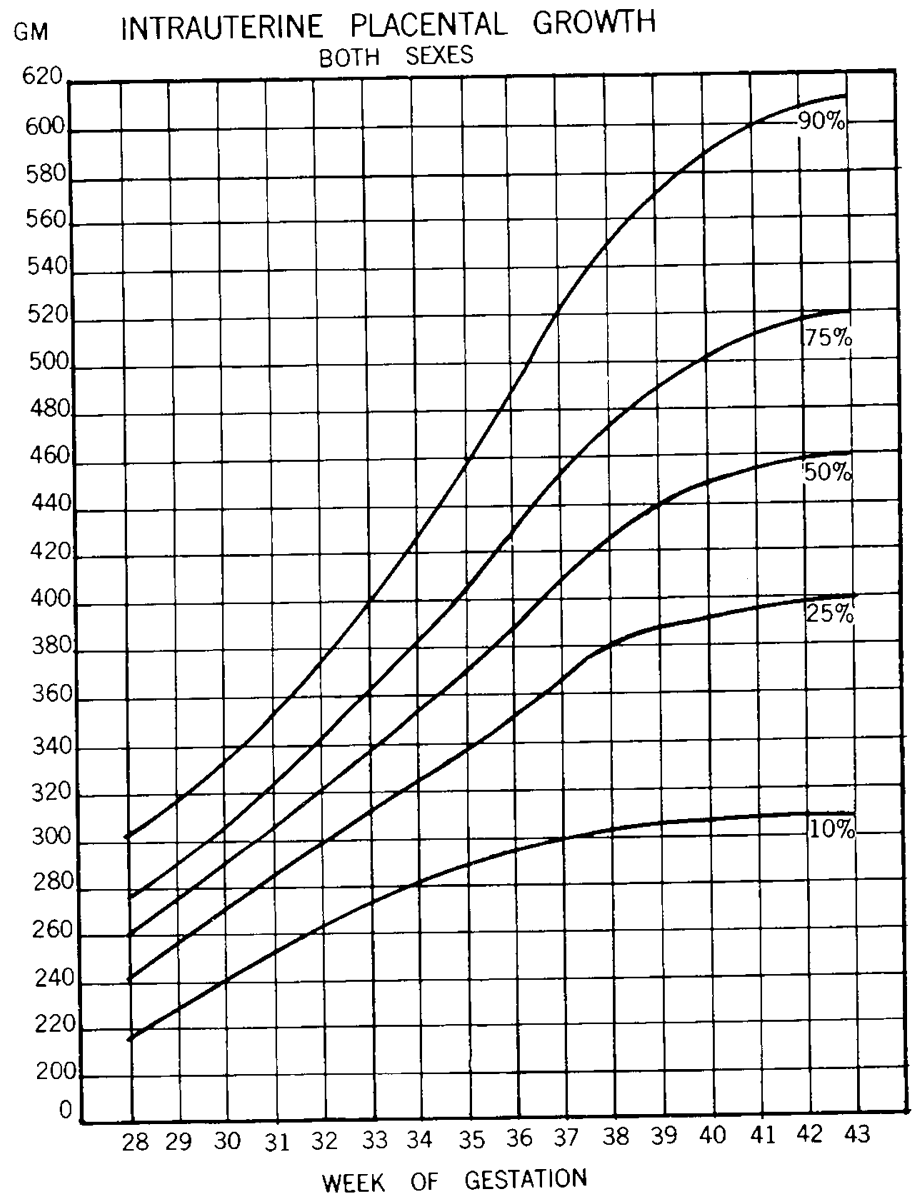

Fig. 4. Placental weight percentiles from $28-43$ weeks of gestation. In most cases, blood was allowed to drain from the organ and clots were removed before weights were taken. 


\section{RESULTS}

The new fetal growth standards are found in Tables 2-5 and Figures 1-4. They include data from single, liveborn infants who survived. All the values were established by the cluster, probability plot method $(3,6)$. Most SD from mean values are much smaller in these new standards than in both previously published standards and in standards that include all the current 48,239 single born survivors (Table 6). These differences between the new and older standards are greater before 38 weeks of gestation than at term.

Both the frequencies and the mortality rates for several common fetal disorders were determined by growth category. All single born infants in the study were included in these analyses. Acute inflammation of the subchorionic plate of the placenta, a marker for amniotic fluid bacterial infections, was somewhat more fre- quent when preterm infants were undergrown than when they were larger for gestational age (Table 7) (9). Perinatal death due to the disorder was most frequent in the most undergrown infants. The perinatal mortality rates decreased markedly with each increase in fetal growth category using Lubchenco growth standards (Table 7). These changes between growth categories were less when the new fetal growth standards were used (Table 7). Results were similar for placenta previa and for abruptio placentae.

\section{DISCUSSION}

Findings in the present study indicate that published fetal growth standards are likely distorted by the inclusion of many growth-retarded fetuses and by cases in which monthly vaginal bleeding in early pregnancy is taken for the last menstrual period. Authors of previous growth standards have made efforts to exclude

Table 6. Birth weights from six sources ${ }^{1}$

\begin{tabular}{|c|c|c|c|c|c|c|c|}
\hline \multirow{2}{*}{$\begin{array}{l}\text { Nearest } \\
\text { week of } \\
\text { gestation }\end{array}$} & \multicolumn{5}{|c|}{ Mean birth wt $(g) \pm 1$ SD } & \multirow{2}{*}{$\begin{array}{l}12 \text { US cities } \\
\text { (all cases) }\end{array}$} & \multirow{2}{*}{$\begin{array}{l}12 \text { US cities (clus- } \\
\text { ter method) }\end{array}$} \\
\hline & Denver & Baltimore & Montreal & Portland & Chapel Hill & & \\
\hline 28 & $1150 \pm 259$ & $1050 \pm 310$ & $1113 \pm 150$ & $1172 \pm 344$ & $1150 \pm 272$ & $1964 \pm 593$ & $1165 \pm 109$ \\
\hline 29 & $1270 \pm 294$ & $1200 \pm 350$ & $1228 \pm 165$ & $1322 \pm 339$ & $1310 \pm 299$ & $2043 \pm 671$ & $1295 \pm 94$ \\
\hline 30 & $1395 \pm 341$ & $1380 \pm 370$ & $1373 \pm 175$ & $1529 \pm 474$ & $1460 \pm 340$ & $2023 \pm 654$ & $1440 \pm 115$ \\
\hline 31 & $1540 \pm 375$ & $1560 \pm 400$ & $1540 \pm 200$ & $1757 \pm 495$ & $1630 \pm 340$ & $2025 \pm 655$ & $1601 \pm 117$ \\
\hline 32 & $1715 \pm 416$ & $1750 \pm 410$ & $1727 \pm 225$ & $1881 \pm 437$ & $1810 \pm 381$ & $2206 \pm 634$ & $1760 \pm 128$ \\
\hline 33 & $1920 \pm 505$ & $1950 \pm 420$ & $1900 \pm 250$ & $2158 \pm 511$ & $2010 \pm 367$ & $2347 \pm 654$ & $1955 \pm 138$ \\
\hline 34 & $2200 \pm 539$ & $2170 \pm 430$ & $2113 \pm 280$ & $2340 \pm 552$ & $2220 \pm 395$ & $2552 \pm 559$ & $2160 \pm 202$ \\
\hline 35 & $2485 \pm 526$ & $2390 \pm 440$ & $2347 \pm 315$ & $2518 \pm 468$ & $2430 \pm 408$ & $2741 \pm 637$ & $2387 \pm 208$ \\
\hline 36 & $2710 \pm 519$ & $2610 \pm 440$ & $2589 \pm 350$ & $2749 \pm 490$ & $2650 \pm 408$ & $2917 \pm 521$ & $2621 \pm 274$ \\
\hline 37 & $2900 \pm 451$ & $2830 \pm 440$ & $2868 \pm 385$ & $2989 \pm 466$ & $2870 \pm 395$ & $2995 \pm 518$ & $2878 \pm 288$ \\
\hline 38 & $3030 \pm 451$ & $3050 \pm 450$ & $3133 \pm 400$ & $3185 \pm 450$ & $3030 \pm 395$ & $3070 \pm 440$ & $3119 \pm 302$ \\
\hline 39 & $3140 \pm 403$ & $3210 \pm 450$ & $3360 \pm 430$ & $3333 \pm 444$ & $3170 \pm 408$ & $3210 \pm 434$ & $3210 \pm 434$ \\
\hline 40 & $3230 \pm 396$ & $3280 \pm 450$ & $3480 \pm 460$ & $3462 \pm 456$ & $3280 \pm 422$ & $3351 \pm 448$ & $3351 \pm 448$ \\
\hline 41 & $3290 \pm 396$ & $3350 \pm 450$ & $3567 \pm 475$ & $3569 \pm 468$ & $3360 \pm 435$ & $3444 \pm 456$ & $3444 \pm 456$ \\
\hline 42 & $3300 \pm 423$ & $3400 \pm 460$ & $3513 \pm 480$ & $3637 \pm 482$ & $3410 \pm 449$ & $3486 \pm 463$ & $3486 \pm 463$ \\
\hline 43 & & $3410 \pm 490$ & $3416 \pm 465$ & $3660 \pm 502$ & $3420 \pm 463$ & $3473 \pm 502$ & $3473 \pm 502$ \\
\hline
\end{tabular}

${ }^{1}$ The final two columns compare values from the present study, all cases vs. those selected by the cluster method.

Table 7. Frequency and mortality from several common perinatal disorders by percentile birth weight category ${ }^{1}$

\begin{tabular}{|c|c|c|c|c|}
\hline & \multicolumn{4}{|c|}{ Birth wt, percentile growth category } \\
\hline & $<10$ & $10-24$ & $25-90$ & $>90$ \\
\hline \multicolumn{5}{|l|}{ Amniotic fluid infection syndrome } \\
\hline \multicolumn{5}{|l|}{ New growth standard (present study) } \\
\hline Frequency of the disorder in $\%$ & $15.1^{2}(154)$ & $11.9 \%(144)$ & $11.0 \%(239)$ & $10.4(441)$ \\
\hline Perinatal mortality from disorder & $123.4^{3}(19)$ & $34.7(5)$ & $37.7(9)$ & $11.3^{4}(5)$ \\
\hline \multicolumn{5}{|l|}{ Lubchenco growth standard } \\
\hline Frequency of the disorder in $\%$ & $15.6(86)$ & $13.9(129)$ & $12.8(449)$ & $8.6^{5}(314)$ \\
\hline Perinatal mortality from disorder & $151.2^{5}(13)$ & $46.5(6)$ & $33.4(15)$ & $6.4^{2}(2)$ \\
\hline \multicolumn{5}{|l|}{ Abruptio placentae } \\
\hline \multicolumn{5}{|l|}{ New Growth Standard } \\
\hline Frequency of the disorder in $\%$ & $9.3^{5}(111)$ & $7.2(97)$ & $4.3(104)$ & $2.4^{5}(129)$ \\
\hline Perinatal mortality from disorder & $252.3(28)$ & $144.3(14)$ & $144.2(15)$ & $100.8(13)$ \\
\hline \multicolumn{5}{|l|}{ Lubchenco Growth Standard } \\
\hline Frequency of the disorder in $\%$ & $9.5^{5}(65)$ & $8.6^{5}(95)$ & $4.8(202)$ & $1.8^{5}(79)$ \\
\hline Perinatal mortality from disorder & $230.8(15)$ & $210.5(20)$ & $138.6(28)$ & $88.6(7)$ \\
\hline \multicolumn{5}{|l|}{ Placenta previa } \\
\hline \multicolumn{5}{|l|}{ New Growth Standard } \\
\hline Frequency of the disorder in $\%$ & $2.5(29)$ & $2.2(30)$ & $2.6(61)$ & $0.9^{5}(51)$ \\
\hline Perinatal mortality from disorder & $241.4^{2}(7)$ & $33.3(1)$ & $32.8(2)$ & $78.4(4)$ \\
\hline Lubchenco Growth Standard & $1.8(13)$ & $2.8(33)$ & $2.2(95)$ & $0.7^{5}(30)$ \\
\hline Frequency of the disorder in $\%$ & $307.7^{2}(4)$ & $90.9(3)$ & $63.2(6)$ & $33.3(1)$ \\
\hline Perinatal mortality from disorder & & & & \\
\hline
\end{tabular}

\footnotetext{
${ }^{1}$ Number of cases are in parentheses. Perinatal mortality: deaths/1000 births.

${ }^{2} P<0.05$ compared with growth percentile category $25-90$.

${ }^{3} P<0.01$ compared with growth percentile category $25-90$.

${ }^{4} P<0.1$ compared with growth percentile category $25-90$.

${ }^{5} P<0.001$ compared with growth percentile category $25-90$.
} 
these latter infants on a case by case basis using clinical histories, results of maternal physical exams, and neonatal physical and neurologic scales of maturation. Such methods appear not to have been entirely successful because all the published standards yield SD from mean birth weight values that are relatively larger in preterm than in term infants. Uterine and placental disorders have long been known to exert their greatest effects on fetal growth late in gestation and we have recently found that maternal calorie intake exerts its greatest influence on fetal growth late in gestation $(5,12,13)$. Thus, variations in fetal growth are greatest near term so relative values for SD from mean birth weight values should progressively increase rather than decrease near term. The cluster method used to construct fetal growth standard in the present study yielded values for SD that are relatively larger in term than in preterm infants.

Changes in perinatal mortality rates between growth categories are less using the new growth standards than using the older ones (Table 7). The frequency of amniotic fluid infections is more closely related to qualitative aspects of maternal diets than to calorie intake and fetal growth. Thus, perinatal mortality rates due to the infections are about the same in dizygous twins and in the single born despite the much higher frequency of growth retardation in the twins $(10,11)$. Nearly complete studies in South Africa show that normal maternal calorie intake during pregnancy and consequent normal fetal growth are no protection against high death rates from the infections when maternal diets are deficient in specific constituents needed to maintain normal antimicrobial activity in the amniotic fluid (13). Thus, the known biology of the disorder offers no basis for the greater differences in perinatal mortality found between growth categories in the older compared with the new growth standards.

The second type of error commonly incorporated into the older fetal growth standards was easily recognized in the present study but means for correcting it are not as satisfactory. Previously published fetal growth standards combine measurements from infants who died in the neonatal period with measurements from those who survived $(1,2,4,7,16)$. The present study found that fetal growth values are significantly larger in preterm infants who survive than in those who die so the new growth standards were based on measurements from survivors. Despite the exclusions, the new growth standards probably retain measurements from a disproportionate number of growth-retarded neonates because most of the disorders responsible for preterm deliveries are associated with retarded fetal growth.
The present study does not call into question the clinical usefulness of the widely used, older fetal growth standards. Rather it points out that they likely include data from both growth-retarded neonates and from some neonates older than their calculated gestational ages. At present, there seems no completely valid method available for determining normal fetal growth standards if such standards must be based on measurements of prematurely born infants.

\section{REFERENCES AND NOTES}

1. Babson, S. G., Behrman, R. E., and Lessel, R.: Fetal growth: Liveborn birth weights for gestational age of white middle class infants. Pediatrics, 45: 937 (1970).

2. Brenner, E. W., Edelman, D. A., and Hendricks, C. H.: A standard of fetal growth for the United States of America. Amer. J. Obstet. Gynecol., 126: 555 (1976).

3. Cassie, R. M.: Some uses of probability paper in the analysis of size frequency distributions. Aust. J. Marine Freshwater Res., 5: 513 (1954).

4. Gruenwald, P.: Growth of the human fetus. I. Normal growth and its variations. Amer. J. Obstet. Gynecol., 94: 1112 (1966).

5. Gruenwald, P.: The Placenta and Its Maternal Supply Line, pp. 1-17 (University Park Press, Baltimore, 1975).

6. Harding, J. P.: The use of probability paper for the graphical analysis of polymodal frequency distributions. J. Marine Biol. Assoc. U. K., 28: 141 (1949).

7. Lindell, A.: Prolonged pregnancy. Acta Obstet. Gynecol. Scand., 35: 136 (1956).

8. Lubchenco, L. O., Hansman, C., Dressler, M., and Boyd, E.: Intrauterine growth as estimated from liveborn birth-weight data at 24 to 42 weeks of gestation. Pediatrics, 32: 793 (1963).

9. Naeye, R. L.: Causes of perinatal mortality in the U. S. Collaborative Perinatal Project. J. A. M. A., 238: 228 (1977).

10. Naeye R. L.: Twins, causes of perinatal death in 12 U.S. and one African city. Amer. J. Obstet. Gynecol., 131: 267 (1978).

11. Naeye R. L., Benirschke, K., Hagstrom, J. W. C., Marcus, C. C.: Intrauterine growth of twins as estimated from liveborn birth-weight data. Pediatrics, 37: (1966).

12. Naeye, R. L., Blanc, W., and Paul, C. P.: Effects of maternal nutrition on the human fetus. Pediatrics, 52: 494 (1973).

13. Naeye, R. L., and Ross, S.: Unpublished data.

14. Niswander, N. R., and Gordon, M.: The Women and Their Pregnancies (W. B. Saunders, Philadelphia, 1972).

15. The Collaborative Study on Cerebral Palsy, Mental Retardation and Other Neurological and Sensory Disorders of Infancy and Childhood Manual (DHEW, USPHS, 1966).

16. Usher R., and McLean F.: Intrauterine growth of liveborn caucasian infants at sea level. J. Pediat., 74: 901 (1969).

17. Appropriate informed consent was obtained for the study.

18. This research was supported by USPHS Contract NO1-NS-3-2311.

19. Requests for reprints should be addressed to: Dr. Richard L. Naeye, Department of Pathology, M. S. Hershey Medical Center, Hershey, PA 17033 (USA)

20. Received for publication April 11, 1977.

21. Accepted for publication December 21, 1977. 